read and many will find that they need to read sentences more than once and to compile a lexicon of the jargon, which is no doubt necessary in this, as in other disciplines.

J. P. Watson Guy's Hospital, London SE1 9RT

\section{Child Sexual Abuse. Informing Practice from Research}

by D. P. H. Jones \& P. Ramchandani. Oxon: Radcliffe Medical Press. 119 pp. ISBN: 1-85775-362-3.

83

CHILD SEXUAL ABUSE

INFORMING PRACTICE From RESEARCH

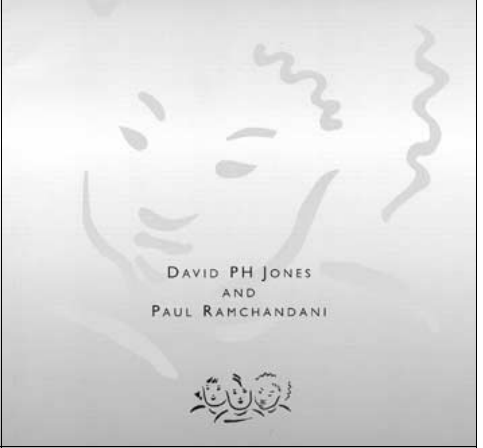

David Jones is a master of the review vignette and his skills emerge again in this important volume on informing practice from research. His qualitative analytical skills were notable in his joint book with McQuiston in 1986, Interviewing the Sexually Abused Child, which preceded the Cleveland Inquiry. He made a similar signal contribution to Child Sexual Abuse - The Principles of Good Practice, which underpinned parts of the Report of The Inquiry into Child Sex Abuse in Cleveland. These skills continue to be exemplified in his editorials for Child Abuse and Neglect. Over the years David Jones' technique has become more sophisticated and his editorials constitute essential reading for those in the field. His coauthor, Paul Ramchandani, has rapidly learnt those skills that have been applied to the task in hand. The net result is that this current volume will constitute a milestone in advances of knowledge and clinical practice in this subject.

The volume is not intended as a definitive comprehensive account, but rather the authors have explored options and selected themes that they considered to be of major significance. It is a model of clarity. Each chapter is introduced by a list of the main questions to be addressed. This is followed by brief accounts of the relevant findings and their evidence base. The authors deliberately avoid cumbersome detail but rather invite the reader to consider the original articles to ascertain for themselves whether or not they would place a similar weight on the evidence as given by the authors in the comments section. An invaluable contribution is the implications on practice section at the end of each chapter.

One is carried comfortably through nine themes - background factors; associated problems for the sexually abused child; referral and early planning; investigation and initial assessment; the Child Protection Conference; comprehensive assessment and planning; implementation, review and de-registration; psychological treatments; and measuring outcome.

It is a deceptively small book because it is so packed with clinically significant information. For the practitioner in the field it is a compulsive and quick read, but not too quick as one is likely to miss many gems. For me, one strength is its willingness to re-examine the many clinical notions, and even some long-standing myths that have emerged over the past decades and have been elevated over time into clinical ideology without any attempt to ascertain if they have a sound evidence-base, or at least face validity. Some readers will not necessarily wish to place the same weight on the evidence as that given by the authors, but when disagreeing they would be wise to provide evidence for the disagreement.

The volume is modern and up-to-date, but like all work in this field some of the notions and emergent guidelines will change with time. Nevertheless, it should be in the library of every social services department and constitute obligatory reading for those working in the field primarily social workers, mental health professionals and paediatricians - also those working in family law.

Israel Kolvin Bowlby Professor (Emeritus) Tavistock Centre, London

\section{Effective Ways of Working with Children and their Families}

Edited by Malcolm Hill. London: Jessica Kingsley Publishers. 1999. 304 pp. f15.95. ISBN: 1-85302619-0.

Children's issues have increasingly made the headlines, be that to do with child abuse, teenage crime, bullying or drug taking and overdosing. More recently children have also found a place on government agendas, particularly since the UK ratified the UN Convention on the Rights of the Child in 1991. However, the main responsibilities for children's welfare and development lie with their families, supported by a range of social, education and health services. Professionals working in these services have not only a social care role in relation to children and their families, but also a social control role Interventions therefore range from support to specific treatment to legal action, including removal of a child from the parental home. This book reviews the state of knowledge about the effectiveness of various forms of interventions with respect to children and their families. It covers a wide spectrum of services and approaches and its contributors are drawn from social work, psychiatry, psychology, education and family mediation. Most contributions have a strong research base, discussing the types of evidence available, noting limitations and pinpointing key findings relevant to practitioners.

The first part of the book deals with more general approaches, such as working with social networks, community-based interventions, family mediation and educational services for children with emotional and behavioural difficulties. A well-written chapter on family therapy reviews the evidence for its efficacy by examining various different outcome studies and concludes that there is strong support for the efficacy of family therapy and parent management-training in the treatment of general child conduct disorder, child aggression, eating disorders and global family problems. The second part of the book concentrates on particular kinds of children, such as working with fostered children and their families, children in residential care and therapeutic work with sexually abused children.

This is an impressive book, bringing together many different findings and data. I recommend it for all professionals working with children, families and the larger system.

K. Eia Asen Consultant Child and Adolescent Psychiatrist, Marlborough Family Service, 38 Marlborough Place, London NW8 OPJ

\section{Books received}

Quality Assurance. A Pathway to Excellence. D. N. T. Sale. Basingstoke \& London: Macmillan Press. 2000. 320 pp. f17.99. ISBN 0-333-74992-8 pb.

Guide to Assessment Scales in Schizophrenia. J. P. McEvoy. London: Science Press Ltd. 2000. 82 pp. £11.95. ISBN 185873-399-5 pb.

Maudsley Discussion Paper No. 9. Adoption as a Placement Choice: Arguments and Evidence. A. Rushton. London: King's College London. 2000. 22 pp. £4.00.

Growing Up Severely Autistic. They Call Me Gabriel. K. Rankin. London: Jessica Kingsley Publishers. 208 pp. £12.95. ISBN 1-85302-891-6 pb.

Coroners' Courts. A Guide to Law and Practice. C. Dorries. Chichester: John Wiley \& Sons. 385 pp. f34.95. 1-84174147-7 hb. 